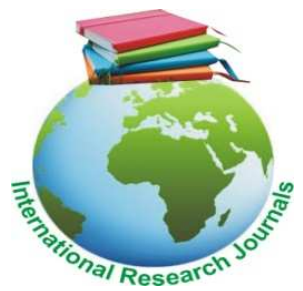

Journal of Medicine and Medical Sciences Vol. 8(7) pp. 088-094, December 2017

DOI: http:/dx.doi.org/10.14303/jmms.2017.186

Available online http://www.interesjournals.org/JMMS

Copyright (C) 2017 International Research Journals

Full Length Research Paper

\title{
Histopathological analysis of salivary gland biopsies in Kumasi: An 8 year retrospective study
}

\author{
${ }^{1}$ Titiloye NA, ${ }^{1}$ Duduyemi BM ${ }^{*},{ }^{2}$ Okai I, ${ }^{1}$ Ossei PPS \\ 1Department of Pathology, Kwame Nkrumah University of Science and Technology, Kumasi, Ghana \\ ${ }^{2}$ Department of Anatomy, Kwame Nkrumah University of Science and Technology, Kumasi, Ghana \\ *Corresponding author's emails: babsdudu@yahoo.com, tundeduduyemi@gmail.com
}

\begin{abstract}
The salivary gland shows wide spectrum of findings on histological examination when they are removed at surgery. The findings range from normal to malignant. The major salivary glands include parotid, submaxillary and sublingual while the others found in many other locations in the head and neck region constitute the minor salivary glands. All cases of salivary gland tissues received at our department of Pathology between the year 2009 and 2016 were selected for this study. Data regarding histological diagnosis, age, sex and location were abstracted. The slides for the cases were retrieved from our archive and the histological diagnoses were revaluated. In cases where the slides were not found, the blocks were retrieved and new sections were cut for histological appraisal. The data obtained were uploaded into excel sheet and descriptive analysis was carried out using SPSS version 23. Results obtained were presented in tables and charts. 371 cases of salivary gland specimens were received during the 8 year period with M:F ratio of 1:1.22 average 46 cases per year. Most of the cases were from the major salivary glands with the most common site being parotid gland $(52 \%)$. The histology showed benign 167 cases (45\%), primary malignant 103 cases (27.8\%), inflammatory and tumour-like 86 cases $(23.2 \%)$ while 4 cases $(1.1 \%)$ were metastatic and 11 cases $(2.9 \%)$ were normal. In the present study, most of our salivary gland biopsies were salivary gland tumours of which benign tumours are much more common than the malignant ones. Pleomorphic adenoma and non-Hodgkin lymphomas were the most common histologic types for the benign and malignant neoplasms respectively
\end{abstract}

Keywords: Salivary Gland, Benign, Inflammatory, Malignant

\section{INTRODUCTION}

The salivary gland shows wide spectrum of findings on histological examination when they are removed at surgery. The findings range from normal to malignant. The Major Salivary glands include parotid, submaxillary and sublingual while the others found in many other locations in the head and neck region constitute the minor salivary glands. Previous study from our centre (Oti et al., 2013) on prevalence of salivary gland tumours of consecutive patients up to year 2010; shows heterogeneous tumours with a mean age of 53.5 years, occurring more in male with tendency to be benign. Over the last 8 years there has been continual diagnosis of lesions in the salivary gland biopsies in our department and a review of the study to include all ranges of diagnosis made on these biopsies is necessary.

Tumours of the salivary glands are uncommon accounting for less than $2 \%$ of all human tumours (Olivera et al., 2015; Dennis et al., 2014) and 2.8-10\% of all head and neck tumours (Bahra et al., 2012; Aliyu et al., 2016; Al-Khateeb and Ababney, 2007) Kumasi cancer Registry age adjusted incidence for salivary gland cancers in female and male are $0.3 \%$ and $0.2 \%$ respectively (Dennis et al., 2014). Location of the salivary glands to some extent play a role in determining the type of lesions seen in the glands, also determine the signs and symptoms and the clinical outcome of management. 


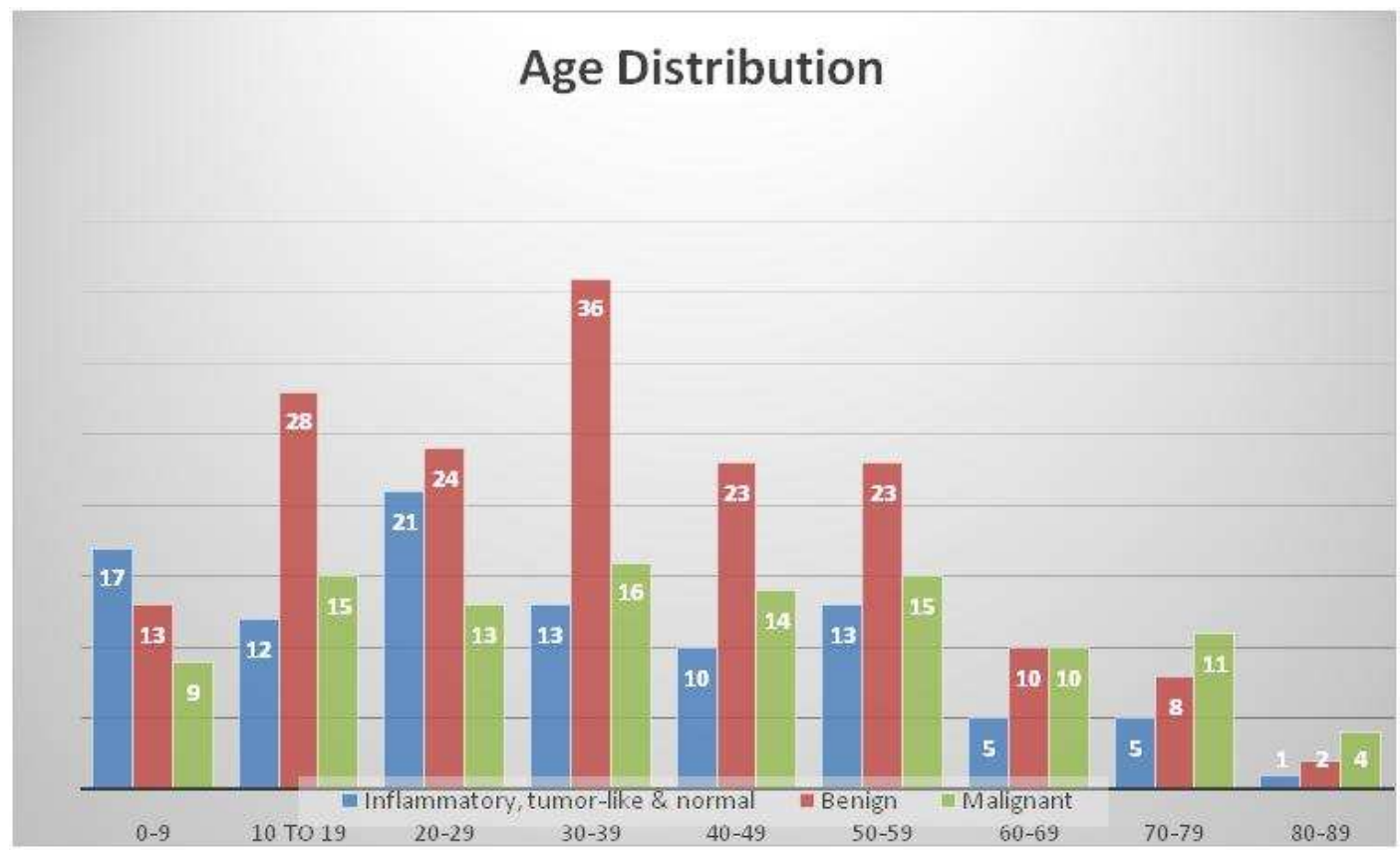

Figure 1: Age distribution of our patients according to histology diagnosis

Most tumours occur in the parotid, submaxillary and the minor salivary glands while sublingual is rarely involved by tumours. Tumours of the salivary glands are commonly benign with pleomorphic adenoma being the commonest variant (Olivera et al., 2015). The parotid and submandibular glands are common site for benign tumours and the sublingual and other minor salivary glands have predilection for malignant tumours (Olivera et al., 2015; Bahra et al., 2012).

The aim of this study is to evaluate the spectrum of diagnosis made on all cases of salivary gland specimen received in our department in the last eight years and use WHO classification to categorize the tumours. The relationship between distinct histopathological phenotypes as seen in the minor and major salivary glands with age and gender of the patients would be evaluated.

\section{MATERIALS AND METHODS}

All cases of salivary gland tissues received at our department of Pathology between the year 2009 and 2016 were selected for this study. Histological number, histological diagnosis and clinical parameters which included age, sex and location were abstracted. The slides for the cases were retrieved from our archive and the histological diagnoses were revaluated. In cases where the slides were not found the blocks were retrieved and new sections were cut for histological appraisal. The data obtained were uploaded into excel spreadsheet descriptive analysis was carried out using SPSS version 23. Results obtained were presented in tables and charts.

\section{RESULTS}

\section{Age distribution and frequency of cases}

A total number of 371 cases of salivary gland specimens were received between 2009 and 2016, a period of 8 years with an average of 46 cases per year. The highest number of cases was seen in 2010 while 2016 recorded the lowest number of cases (Figure 1). Table 2 shows the age distribution with the age range being 6 months to 88 years and mean age of 37 years (SD 20.84). The modal age group is $30-39$ years constituting $17.5 \%$ of the cases. The mean ages for benign and malignant tumours were 36.4 years and 41.6 years respectively. In all the age groups before 60 years, the benign cases were more than the malignant cases while malignant cases predominates after 60 years. In the age group of 0 9years, tumour like and inflammatory condition predominates accounting for 17 out of 19 cases. Malignant cases are more common than the benign ones after the age of 60 years.

\section{Frequency distribution of salivary gland lesion}

This is as shown in figure 2. There were 2 peaks at 2010 and 2015 representing 63 and 56 cases respectively 
090 J. Med. Med. Sci.

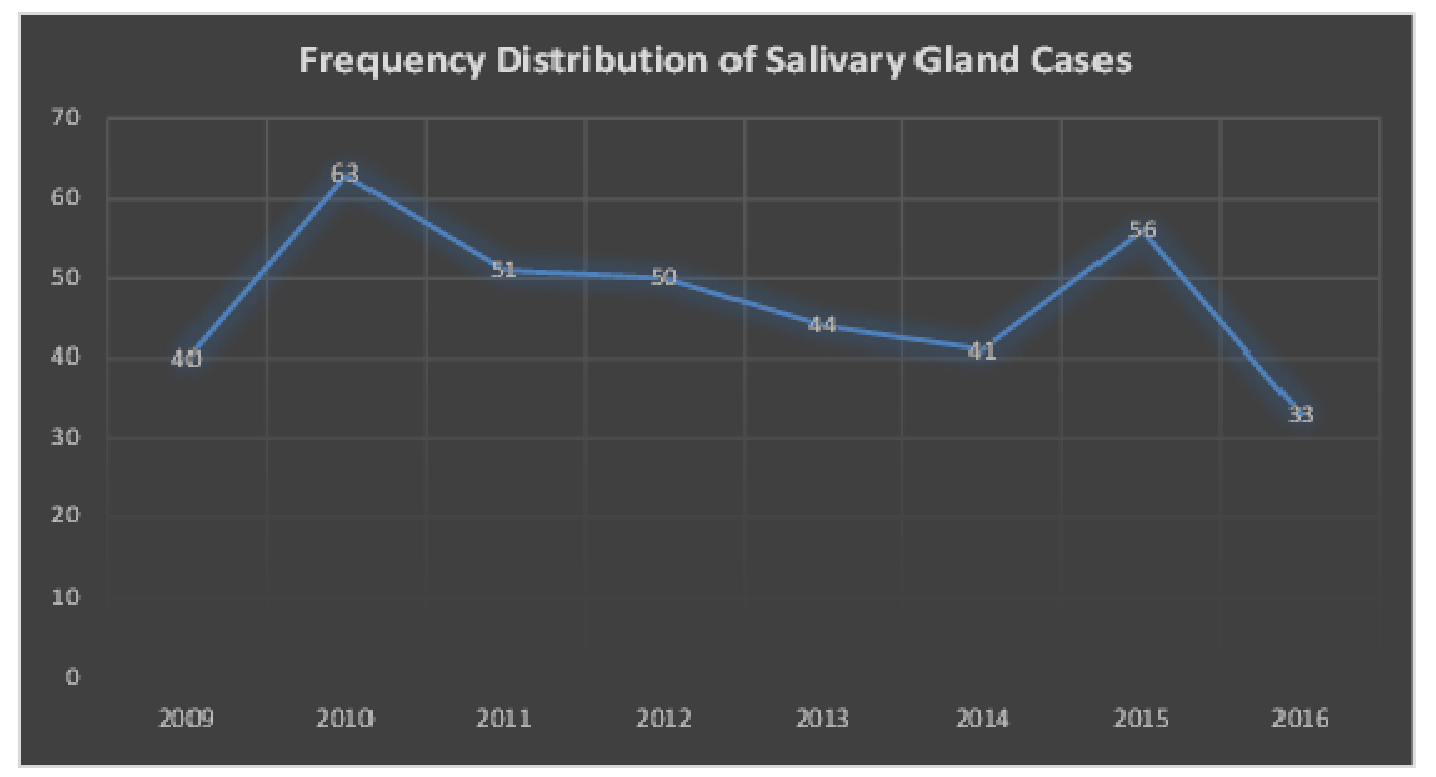

Figure 2: Yearly distribution of salivary gland lesions over 8 year period

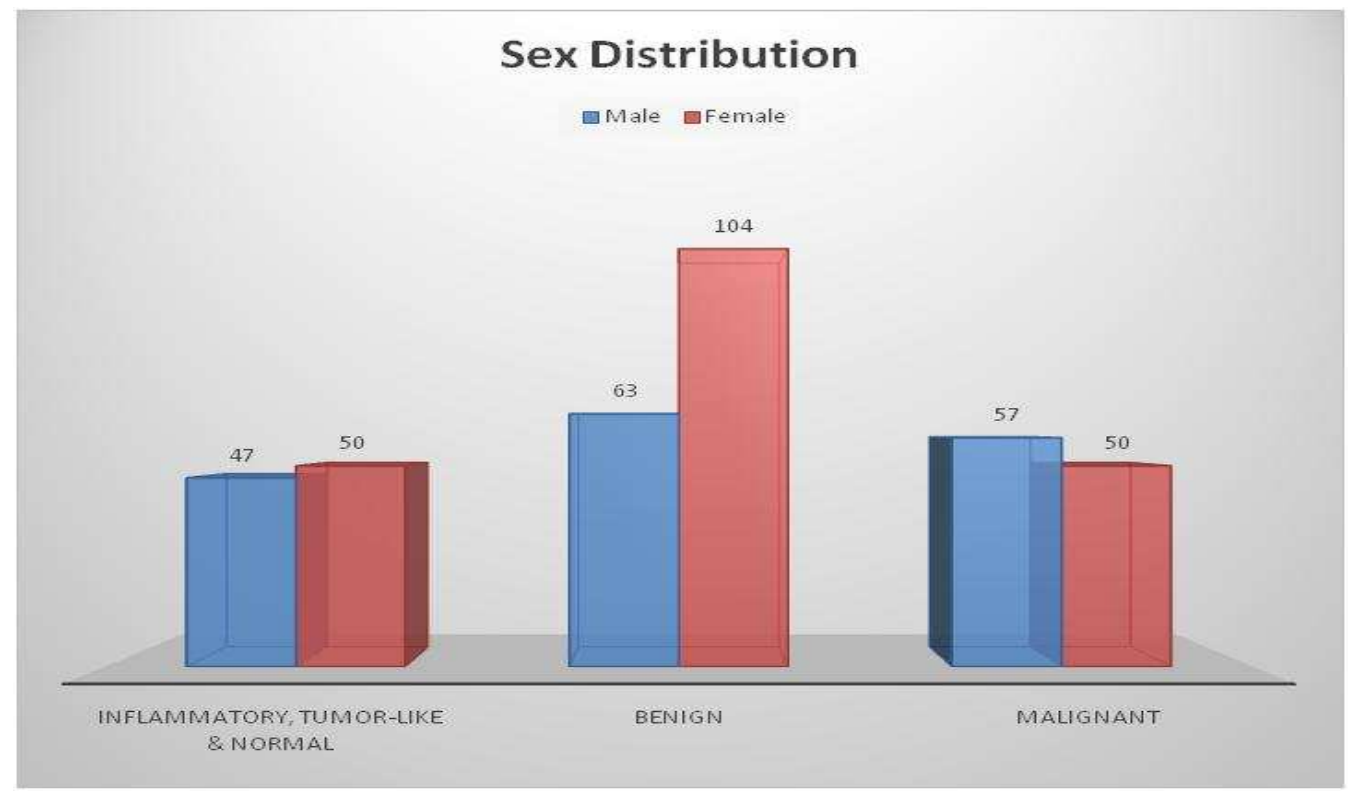

Figure 3: Sex distribution of our patients according to histology diagnosis

while the least number of cases were seen in 2016 (33 cases)

\section{Sex distribution}

Figure 3 shows the sex distribution of salivary gland specimens during the study period. Out of a total of 371 samples, 167 were males while 204 were females with male to female ratio of $1: 1.22$. There was female preponderance in inflammatory, tumour-like as well as benign lesions; however there was a slight reversal of this in the malignant lesions.

The $M: F$ ratio in the benign, inflammatory and tumourlike lesions was 1:1.2 while that of malignant lesions was 1.14:1. 
Table 1: Histological diagnosis of benign tumours according to site

\begin{tabular}{|c|c|c|c|c|c|c|}
\hline Variant & Parotid & Submandibular & Sublingual & Minor & Unspecified & Total \\
\hline Pleomorphic Adenoma & 72 & 33 & & 3 & 3 & 111 \\
\hline Basal Cell Adenoma & 12 & 2 & & & & 14 \\
\hline Warthin's tumour & 7 & 2 & & & & 9 \\
\hline Lymphoepithelial lesions & 6 & 1 & & & & 7 \\
\hline Lipoma & 1 & 5 & & & & 6 \\
\hline Benign cystic teratoma & 2 & 3 & & & & 5 \\
\hline Papilloma & & & & 3 & & 3 \\
\hline Carvenous Haemangioma & 2 & & & & & 2 \\
\hline Neurofibromatosis & 2 & & & & & 2 \\
\hline Benign Lymphangioma & 1 & & & & & 1 \\
\hline Oncocytoma & 1 & & & & & 1 \\
\hline Ameloblastoma & & 1 & & & & 1 \\
\hline Cystic Hygroma & & 2 & & & & 2 \\
\hline Dermoid Cyst & & 1 & & & & 1 \\
\hline Fibromyolipoma & & 1 & & & & 1 \\
\hline Neuroblastoma & & 1 & & & & 1 \\
\hline Total & 106 & 52 & 0 & 6 & 3 & 167 \\
\hline
\end{tabular}

Table 2: Histological diagnosis of malignant tumours according to site

\begin{tabular}{|c|c|c|c|c|c|c|}
\hline Variant & Parotid & Submandibular & Sublingual & Minor & Unspecified & Total \\
\hline Non-Hodgkins lymphoma & 4 & 15 & & 1 & & 20 \\
\hline Adenoid Cystic Carcinoma & 9 & 4 & & & 1 & 14 \\
\hline Mucoepidermoid Carcinoma & 12 & 2 & & & & 14 \\
\hline Adenocarcinoma & 4 & 4 & & 3 & & 11 \\
\hline Squamous cell carcinoma & 7 & 4 & & & & 11 \\
\hline Undifferentiated carcinoma & 6 & 3 & & & 1 & 10 \\
\hline Acinic cell carcinoma & 6 & & & & & 6 \\
\hline Hodgkin lymphoma & 2 & 3 & & & & 5 \\
\hline Myoepithelial Carcinoma & 5 & & & & & 5 \\
\hline Adenosquamous Carcinoma & 3 & 2 & & & & 5 \\
\hline Salivary duct carcinoma & 1 & & & & & 1 \\
\hline $\begin{array}{l}\text { Immature Malignant Teratoma } \\
\text { Metastatic: }\end{array}$ & & 1 & & & & 1 \\
\hline Malignant Melanoma & 3 & 1 & & & & 4 \\
\hline Total & 62 & 39 & 0 & 4 & 2 & 107 \\
\hline
\end{tabular}

\section{Site distribution of salivary gland lesions}

Most of the cases of the salivary gland specimens reviewed were from the major salivary glands with the parotid gland recording the highest frequency of 193 cases (52\%).

One hundred and fifty five cases (41.8\%) were from submandibular gland while the sublingual recorded the lowest number of $5(1.3 \%)$. The minor salivary glands recorded 10 cases $(2.7 \%)$ while 8 cases $(2.1 \%)$ were unspecified (Tables 1 and 2).

\section{Histological diagnosis}

The commonest types of lesions seen in the salivary gland were grouped as benign with a total of 167 cases (45\%). Primary malignant cases were 103 cases $(27.8 \%)$ 
092 J. Med. Med. Sci.

and Inflammatory and tumour like cases were 86 cases $(23.2 \%)$. While 4 cases $(1.1 \%)$ were metastatic, 11 cases $(2.9 \%)$ were normal (Figure 3$)$.

The representation of these entities in the various glands shows similar pattern with a slight variation. Parotid gland recorded the highest number of benign cases, 106 (54.9\%). A high number of cases, 59 (38.1\%) from the submandibular were inflammatory and tumour like. All the cases in the sublingual glands were inflammatory and tumour like. In the minor salivary gland, there were more malignant cases than benign ones (4 out of 10) (Tables 1 and 2).

\section{Clinical indication for surgery}

Indication for Surgical removal of Salivary gland in KATH ranges from obvious localisation of masses in most cases with the Surgeon suggesting possible diagnosis ranging from inflammatory conditions to benign to malignant. Some Salivary glands were also removed based on congenital anomalies.

\section{DISCUSSION}

Epidermiological data reported specifically for salivary gland biopsies examined at clinical institution sites in Ghana is limited. The few published reports available are by (Oti et al., 2013) and (Parkin and Boamah, 2009) whose retrospective study focused on salivary gland tumours seen at Komfo Anokye and Korle Bu Teaching Hospitals respectively at different time periods. Diagnosis of various lesions in the salivary glands at the Komfo Anokye Teaching Hospital is still common. An update on institutional data to reflect the most recent pattern in diagnosis of all cases of salivary gland biopsies is imperative to contribute to general data required for population prevalence estimates and also to track changes in the characteristics of tumours in the future. The current retrospective study reviewed $\$ 371$ cases examined at KATH in the last eight years from 2009. For the period under review, the spectrum of diagnoses included 11 (2.9\%) normal, 86 (23.2\%) inflammatory and tumour-like, and 274 (73.9\%) tumour cases. In (Oti et al., 2013) report, 121 salivary gland tumours (SGTs) were diagnosed at the same centre in their twelve year review. This appears to suggest more than 2-fold increase in the incidence of these tumours at the centre over the years under current review.

In age-related analysis of cases, 276 (74.4\%) of all patients were in the first to fifth decades of life with a peak in the third decade while $54(14.5 \%)$ were in sixth to eighth decades. 39 (10.5\%) patients were less than 10 years of which $22(56.4 \%)$ had SGTs and 17 (43.6\%) were inflammatory or tumour-like. Majority of cases presenting with SGTs were in the fourth and fifth decades with mean ages for benign and malignant cases being 36.4 years and 41.6 years respectively. Benign SGTs have been reported to be more common in third decade of life in studies from Nigeria (Aliyu et al., 2016; Adedeji et al., 2014), Ghana (Oti et al., 2013) and Uganda (Vahahula, 2004). A number of studies (Oti et al., 2013; Parkin and Boamah, 2009; Adedeji et al., 2014) Adedeji et al., 2014; Khattak et al., 2016; Pinkston and Cole, 1999; Ito et al., 2005; Tian et al., 2010; Subhashraj, 2008; $\mathrm{Li}$ et al., 2008) have shown the fifth decade and beyond as the peak for malignant SGTs, similar to our observation. However, some studies in Africa (Aliyu et al., 2016; Vahahula, 2004) and Asia (Al-Khateeb and Ababney, 2007; Tian et al., 2010) contrast our finding and that malignant SGTs are seen more in the fourth decade of life. It is possible that the variation in the number of cases analysed in the different reports may underpin these differences. Further it is noteworthy, that the agerelated characteristics of SGTs agree in many aspects to several studies reported in literature, especially in the African setting. For example the age profile of our cases supports (Yaor, 2010) view that generally young patients present with SGTs in many parts of Africa compared to reported ages in the Western countries where benign and malignant lesions are common in patients from 50 years and beyond (Ochicha et al., 2009).

Generally, there is high incidence of benign relative to malignant lesions among SGTs from worldwide reports although few studies (Bahra et al., 2012; Aliyu et al., 2016; Poomsawat et al., 2004) found more malignant cases than benign. From our series the ratio of benign-tomalignant tumours was $1.6: 1$, less than ratios noted for many populations outside of the African continent such as Asia (Khattak et al., 2016; Toida et al., 2005) USA (Pinkston and Cole, 1999), UK (Jones et al., 2008) and Brazil (Ito et al., 2005; Vargas et al., 2002). Our ratio is comparable to a study from Nigeria (Ochicha et al., 2009), albeit a little higher than two studies from East Africa (Vahahula, 2004; Masanja et al., 2003) where the ratio was approximately $1: 1$. The most frequent histologic type for benign neoplasms in our series was pleomorphic adenoma (PA) with incidence of $66.5 \%$ which is consistent with worldwide reported incidence rates (Oti et al., 2013; Olivera et al., 2015; Bahra et al., 2012; Aliyu et al., 2016; Al-Khateeb and Ababney, 2007; Parkin and Boamah, 2009; Adedeji et al., 2014; Vahahula, 2004; Khattak et al., 2016; Ito et al., 2005; Tian et al., 2010; Subhashraj, 2008; Li et al., 2008; Toida et al., 2005; Jones et al., 2008; Vargas et al., 2002; Masanja et al., 2003; Otoh et al., 2005; Shaikh et al., 2010; Ergicho and Ergisho, 2003; Zaman et al., 2014). Basal cell adenoma and Warthin's tumour followed in order after PA. Although many reports (Bahra et al., 2012; Al-Khateeb and Ababney, 2007); Shaikh et al., 2010; Zaman et al., 2014; Hyam et al., 2004) depict mucoepidermoid and adenoid cystic carcinomas as the most frequent salivary malignancies, Non-Hodgkin's lymphoma (NHL) with 
incidence of $7.3 \%$ of our SGT series, was the most common malignant lesion, diverging from (Oti et al., 2013) study at the same site where adenoid cystic was the most prevalent. Furthermore, the NHL had preference for the submandibular gland as opposed to the parotid which is generally acclaimed to be dedicated to NHLs of the salivary glands (De Cesare et al., 1997; Kolokotroni et al., 2005). Also few cases of ectopic tumours (1.8\%) were seen in our series.

Variation in the study periods and sample size may have contributed to the differences in prevalent malignant SGT type among the various studies. The mucoepidermoid and adenoid cystic carcinomas followed $\mathrm{NHL}$ each with $5 \%$ incidence in our cases.

With regard to site of SGT, approximately $95 \%$ of cases in our data were of major salivary glands with the minor glands taking $3.6 \%$ while $1.8 \%$ were unspecified. There was a high frequency of SGTs from the parotid with some $61 \%$, being analogous to reports from Kenya (Onyango et al., 1992), Nigeria (Adedeji et al., 2014; Otoh et al., 2005; Silas and Echejoh, 2009), Uganda (Vahahula, 2004), Tanzania (Masanja et al., 2003), Zimbabwe (Chidzonga et al., 1995), other works from Ghana (Oti et al., 2013; Parkin and Boamah, 2009), Pakistan (Khattak et al., 2016; Shaikh et al., 2010; Zaman et al., 2014), China (Tian et al.,2010; Li et al., 2008), India (Subhashraj, 2008), Brazil (Ito et al., 2005; Vargas et al., 2002), UK (Jones et al., 2008) and USA (Pinkston and Cole, 1999); followed by submandibular $(33.2 \%)$. Tumours of the sublingual was absent in the present study which corroborates the widely held view that the gland is the least receptive of major salivary glands to tumours. PA was the commonest benign lesion in both the parotid and submandibular at approximate rates of $40 \%$ and $20 \%$ respectively, while mucoepidermoid carcinoma was the frequently diagnosed malignant lesion of the parotid. Adenocarcinoma was seen more among the malignant neoplasms of the minor salivary glands in our study.

From sex distribution perspective, the male to female ratio of our biopsies was $M: F=1: 1.22$. There were more females than males with SGTs in our study population, which is similar to previous studies done in Africa (Onyango et al., 1992; Silas and Echejoh, 2009; Chidzonga et al., 1995). The incidence of SGTs was $56.2 \%$ and $43.8 \%$ for females and males respectively. This pattern translated into the prevalence of benign lesions where females reserved some $62.2 \%$ of benign biopsies. However, the penchant for malignant SGTs in our series was retained by males in $53.2 \%$ of malignant cases.

Again, there appeared to be about equal affinity for inflammatory and tumour-like conditions among both sexes in this study. Reports vary on gender characteristics of salivary gland specimens in particular SGTs. For instance, in Nigeria (Masanja et al., 2003) and Tanzania (Masanja et al., 2003), SGTs were more common in males unlike ours and others where they are slightly female preponderance. In the African studies, there seem to be the suggestion that female affinity for SGTs may partly be connected to cultural beliefs and socioeconomic status (Silas and Echejoh, 2009).

\section{CONCLUSION}

In the present study, most of our salivary gland biopsies were salivary gland tumours of which benign tumours are much more common than the malignant ones. Pleomorphic adenoma and non-Hodgkin lymphomas were the most common histologic types for the benign and malignant neoplasms respectively. Most patients with SGTs were young adult to middle-age. Our findings parallel many reports from sub-Saharan Africa to a greater extent.

\section{REFERENCES}

Adedeji TO, Sogebi OA, Tobih JE (2014). Clinico-Pathologic Spectrum of Salivary Gland Tumours and Its Management in a Suburban Tertiary Centre, Adv. Biores, 5(2):124-129.

Aliyu D, Iseh RK, Sahabi MS (2016). Pattern of Salivary Gland Tumour in Sokoto, North Western Nigeria. Intl. J. Clinical Med., 7, 347-352

Al-Khateeb TH, Ababney KT (2007). Salivary Gland in North Jordanians: A descriptive study. Oral Surgery, Oral Medicine, Oral Pathology, Oral Radiology and Endodontics, 103, 53-59.

Bahra J, Butt F, Dimaba E (2012). Pattern of Salivary gland tumours at a Uni. Teach. Hospital in Kenya. OJST, 2, 280-285.

Chidzonga MM, Lopez-Perez VM, Portilla-Alvarez AL (1995). Salivary gland tumors in Zimbabwe: Report of 282 cases. International J. Oral and Maxillofacial Surgery,24:293-297.

De Cesare A, Bononi M, Atella F, Angelini M, Lauretti C (1997). Primary non-Hodgkin lymphoma of the parotid gland. Panminerva Med;39:228-32.

Dennis OL, Baffour A, Amoako YA (2014). Cancer incidence in Ghana, 2012: evidence from a population- based cancer registry. BMC Cancer 14:362

Ergicho B, Ergisho B. Pattern of salivary gland tumors in Ethiopia and non-western countries. Ethiop Med J. 2003;41: 235-44.

Hyam DM, Veness MJ, Morgan GJ (2004). Minor salivary gland carcinoma involving the oral cavity or oropharynx. Aust Dent J.49:16-9.

Ito FA, Ito K, Vargas PA, d'Almeida OP, Lopes MA (2005). Salivary gland tumors in a Brazilian population: a retrospective study of 496 cases. Int. J. Oral Maxillofac. Surg.; 34: 533-536

Jones AV, Craig GT, Speight PM, Franklin CD (2008). The range and demographics of salivary gland tumours diagnosed in a UK population Oral Oncology, 44: $407-417$.

Khattak MS, Ahmad S, Noman N (2016). The Histolopathological Pattern of Salivary Gland, Gomal J Med Sci; 14 (4): 203-7.

Kolokotroni A, Konstantinou N, Christakis I, Papadimitriou P, Matiakis A, Zaraboukas T, Antoniades D (2005). Localized B-cell non-Hodgkin's lymphoma of oral cavity and maxillofacial region: A clinical study. Oral Surg Oral Med Oral Pathol Oral Radiol Endod; 99:303-10

Li L, Li Y, Wen Y, Liu H, Zhao H (2008). Clinical analysis of salivary gland tumor cases in West China in past 50 years, Oral Oncology, 44:187 - 192.

Masanja MI, Kalyanyama BM, Simon ENM (2003). Salivary Gland Tumors in Tanzania, East African Medical J., 80 (8): 429-434

Ochicha O, Malami, S, Mohammed A, Atanda A (2009). A histopathologic study of salivary gland tumors in Kano, northern Nigeria. Indian J Pathol Microbiol 52:473-476. 
094 J. Med. Med. Sci.

Olivera FA, Duarte EC, Taveira EC (2015). A review of 599 cases in a Brazilian population. Head and Neck Pathology, 3, 371-275.

Onyango JF, Awange DO, Muthamia JM, Muga BIO (1992). Salivary Gland tumors in Kenya. East Africa Medical J., 69: 525-530.

Oti AA, Donkor P, Obiri-Yeboah S (2013). Salivary gland tumours at Komfo Anokye Teaching Hospital, Ghana. Surgical Science, 4, 135139.

Otoh EC, Johnson NW, Olasoji H, Danfilo IS, Adeleke OA (2005). Salivary gland neoplasms in Maiduguri, north-eastern Nigeria. Oral Dis.;11: 386-91.

Parkin G, Boamah MO. Tumours of the Salivary Gland in Ghana, Asian J Oral Maxillofac Surg. 2009;21:96-100.

Pinkston JA, Cole P (1999). Incidence rates of salivary gland tumors: Results from a population-based study Otolaryngology-Head and Neck Surgery,120: 834-40.

Poomsawat S, Punyasingh J, Weerapradist W (2004). A retrospective study of 60 cases of salivary gland tumors in a Thai population. Quintessence Int.; 35:577-81.

Shaikh, AM, Kehar, SI (2010), Tariq, N. Spectrum of salivary gland lesions and frequency of Adenoid cystic carcinoma in Salivary glands and extra salivary sites. Pakistan Journal of otolaryngology, 26:37-39.

Silas OA, Echejoh GO, Manasseh AN, Mandong BM (2009). Patterns of malignant salivary gland tumours in Jos Uni. Teach. Hospital (JUTH), Jos: A ten-year retrospective study. Nigerian J. Med. 18, 282-285.
Subhashraj K (2008). Salivary gland tumors: a single institution experience in India, British Journal of Oral and Maxillofacial Surgery, 46: 635-638

Tian Z, Li L, Wang L, Hu Y, Li J (2010). Salivary gland neoplasms in oral and maxillofacial regions: a 23- year retrospective study of 6982 cases in an eastern Chinese population

Toida M, Shimokawa K, Makita H, Kato K, Kobayashi A, Kusunoki Y, Hatakeyama D, Fujitsuka H, Yamashita T, Shibata T (2005). Intraoral minor salivary gland tumors: a clinicopathological study of 82 cases. Int. J. Oral Maxillofac. Surg.; 34: 528-532

Vahahula EAM (2004). Salivary gland tumors in Uganda: clinical pathological study Afr Health Sci. 4(1): 15-23.

Vargas PA, Gerhard R, Araújo-Filho VJF, De'Castro IV (2002). Salivary gland tumors in a Brazilian population: a retrospective study of 124 cases. Rev. Hosp. Clín. Fac. Med. S. Paulo 57(6):271-276.

Yaor MA (2010). The pattern of presentation of salivary gland tumors in Africa: A review of published reports. Ear Nose Throat J. 89(2):E1721.

Zaman S., Sarosh M, Omer C, Mahvish H, Mehreen N (2014). Salivary Gland Tumors: A Review of 91 Cases, J Ayub Med Coll Abbottabad: 26 (3):361-363. 